\title{
Comparison of the effect of regular and probiotic cake (Bacillus coagulans) on salivary $\mathrm{pH}$ and Streptococcus mutans count
}

\section{Porównanie wpływu spożywania ciastek zwykłych i probiotycznych (Bacillus coagulans) na pH śliny i liczbę Streptococcus mutans}

\author{
Maryam Koopaie ${ }^{1, A-E}$, Mahnaz Fatahzadeh ${ }^{2, C-F}$, Sana Jahangir1 ${ }^{1, B-D}$, Ronak Bakhtiari ${ }^{3, B, E}$ \\ ${ }^{1}$ Department of Oral Medicine, School of Dentistry, Tehran University of Medical Sciences, Iran \\ ${ }^{2}$ Department of Diagnostic Sciences, Rutgers School of Dental Medicine, Newark, USA \\ ${ }^{3}$ Department of Pathobiology, Tehran University of Medical Sciences, Iran \\ A - research concept and design; B - collection and/or assembly of data; $\mathrm{C}$ - data analysis and interpretation; \\ $D$ - writing the article; $E$ - critical revision of the article; $F$ - final approval of the article
}

Address for correspondence

Ronak Bakhtiari

E-mail: rounakbakhtiari@yahoo.com

\section{Funding sources}

None declared

Conflict of interest

None declared

\section{Acknowledgements}

This study was funded and supported by the International Campus of Tehran University of Medical Sciences (IC-TUMS), Iran.

\section{Received on August 12, 2018 \\ Reviewed on October 18, 2018 \\ Accepted on November 14, 2018}

Published online on March 15, 2019

\section{Cite as}

Koopaie M, Fatahzadeh M, Jahangir S, Bakhtiari R. Comparison of the effect of regular and probiotic cake (Bacillus coagulans) on salivary $\mathrm{pH}$ and Streptococcus mutans count. Dent Med Probl. 2019;56(1):33-38. doi:10.17219/dmp/99757

D0I

10.17219/dmp/99757

Copyright

○ 2019 by Wroclaw Medical University This is an article distributed under the terms of the Creative Commons Attribution Non-Commercial License (http://creativecommons.org/licenses/by-nc-nd/4.0/)

\begin{abstract}
Background. Dental caries is considered the most common infectious disease in humans worldwide. Cariogenesis is the outcome of a complex interaction between the host's oral flora and diet. The consumption of snacks such as cake, which have the potential to promote dental caries, has increased.

Objectives. The aim of this study was to investigate the effect of including probiotic bacteria (Bacillus coagulans - B. coagulans) in consumed snack cake on the Streptococcus mutans (S. mutans) count and salivary pH.

Material and methods. We conducted a randomized, double-blind, cross-sectional cohort study on 40 healthy volunteers. The subjects were divided into 2 groups. In the $1^{\text {st }}$ group, the subjects consumed probiotic cake as breakfast for 1 week and then, following a 4-week wash-out period, consumed regular cake as breakfast for 1 week. In the other group, the administration of probiotic and regular cake was reversed. For both groups, samples of at least $5 \mathrm{~mL}$ of non-stimulated saliva were collected using the spitting technique before and after the $1^{\text {st }}$ and the $6^{\text {th }}$ week. A colony counter was used to determine the number of S. mutans colonies. Salivary pH was measured before eating (8-9 a.m.).

Results. We detected no statistically significant difference in the $S$. mutans count before and after the consumption of probiotic cake, but noted a statistically significant difference in the count before and after the consumption of regular cake. We did not detect a significant difference in salivary pH with respect to the consumption of probiotic and regular cake, although the consumption of both foods caused a drop in salivary pH.
\end{abstract}

Conclusions. The addition of probiotic bacteria to sweet snack cake caused a minimal increase in the salivary count of $S$. mutans, a bacterial species with a definite role in cariogenesis, but did not impact salivary $\mathrm{pH}$. Since probiotic cake has a slight impact on the $S$. mutans count, it is preferred over regular cake as a snack food.

Key words: salivary pH, Streptococcus mutans, Bacillus coagulans

Słowa kluczowe: pH śliny, Streptococcus mutans, Bacillus coagulans 


\section{Introduction}

Probiotics are a group of live microorganisms that can have salutary effects on the host's health when properly supplemented or added to food. ${ }^{1}$ Probiotics have a variety of effects, including immunity enhancement. ${ }^{2}$ The latter may be achieved by stimulating the phagocytic leukocytes, increasing the secretion of immunoglobulin $\mathrm{A}$ (IgA), and affecting the production and activity of enzymes. In the gastrointestinal tract, probiotics help maintain the balance within the digestive tract and improve mucosal immunity. ${ }^{3,4}$ The benefits of probiotics are facilitated through several mechanisms, including the alteration of the flora composition and immunomodulation. ${ }^{5}$ The oral cavity is an extremely complex ecosystem with 700 bacterial species, 30 fungal species, several species of protozoa, and intracellular viruses. ${ }^{6}$ Any factor perturbing the balance of these species can potentially affect oral health. Multiple studies have confirmed the potential impact of probiotics on regulating oral microflora, supporting a role for probiotics in the prevention of gingivitis, periodontitis, recurrent aphthous stomatitis, oral candidiasis, and dental caries. ${ }^{7-9}$

Streptococcus mutans (S. mutans) is an acidogenic bacterium and one of the major etiologic factors in dental caries. ${ }^{10}$ Probiotic species, such as Lactobacillus rhamnosus, Lactobacillus acidophilus, Lactobacillus casei, Lactobacillus reuteri, and Bifidobacterium animalis subsp. lactis $(B b-12)$ can suppress the growth of $S$. mutans. ${ }^{11}$ An in vitro study confirmed the growth inhibition of salivary $S$. mutans evoked by sucrose-containing commercial probiotics. ${ }^{12}$ There is also an in vivo study supporting the effect of probiotic ice cream on the reduction of the $S$. mutans count. ${ }^{13}$ In vivo studies using dairy products also demonstrated a significant reduction in the salivary S. mutans count. ${ }^{14,15}$

There is evidence that lactic acid-producing bacteria, and especially the Bacillus species, remain stable in heat and maintain their activity after baking. ${ }^{16}$ The stability of these bacteria is facilitated by the presence of heat-resistant spores ${ }^{17}$ Bacillus coagulans - B. coagulans (Lactobacillus sporogenes) is a gram-positive, spore-forming, facultative anaerobe, which resists high pressure and temperature, and can function as a probiotic of choice in nondairy products. ${ }^{16}$ Other probiotic microorganisms, such as Lactobacillus reuteri, Lactobacillus acidophilus and Bifidobacterium are not spore-forming, and therefore are sensitive to temperature, pressure and stomach acid. $\mathrm{Ba}$ cillus coagulans is a probiotic approved by the U.S. Food and Drug Administration (FDA) for use in animals and humans. ${ }^{18}$ Bacillus coagulans has been shown to increase the antimicrobial properties of proteins as well as to decrease the clinical signs of induced rheumatoid arthritis in rats. ${ }^{19}$ In this novel study, we used cake as the carrier of $B$. coagulans in order to evaluate the impact of probiotics on salivary $\mathrm{pH}$ and the $S$. mutans count.

\section{Material and methods}

This study was reviewed and approved by the Ethics Committee of Tehran University of Medical Sciences (IR.TUMS.DENTISTRY.REC.1396.2754). The people involved in this study were informed about the study and all of them signed the informed consent forms. All volunteers were from the same geographical region and had a comparable socioeconomic status. The study was a randomized, double-blind, crossover trial. Following informed consent, a total of 40 healthy adults without gingivitis, periodontal disease or active caries were enrolled. Excluded from participation were pregnant females, women using contraceptives, and subjects using xylitol gum, probiotic products, corticosteroids, or antibiotics within 3 months of the study initiation. Prior to the start, the subjects were provided oral hygiene instruction, issued toothbrushes, toothpaste and dental floss, and asked to maintain thorough oral health care for 2 weeks. A questionnaire was used to collect information about demographics, oral and general health, oral hygiene practices (frequency of brushing, flossing, mouthwash use, etc.), nutritional habits (consumption of sweet and sour foods), and social history (tobacco and alcohol consumption) from each participant. Our study followed a rigorous selection process and recorded all the behaviors considered likely to affect the $S$. mutans count.

The subjects were divided into 2 groups. Prior to the start of the project in both groups, a minimum of $5 \mathrm{~mL}$ of saliva was collected from each subject using the spitting method (the subjects allowed saliva to gather in the mouth for $60 \mathrm{~s}$ and then spit it into a sterile container; this process continued for a total time of $5 \mathrm{~min}$ ). These specimens were used to determine $\mathrm{pH}$ and the $S$. mutans count at baseline. The subjects were asked to refrain from actions that affect the secretion of saliva, such as eating, drinking and smoking. Sampling was performed before breakfast and at a specific time (8-9 a.m.) to maintain consistency with the circadian rhythm. The latter is known to impact the salivary flow rate, microbial dilution and salivary composition (IgA, cortisol, etc.). In the $1^{\text {st }}$ group, the subjects consumed $70 \mathrm{~g}$ of probiotic cake containing the probiotic bacteria B. coagulans (Dorna Food Industrial Group, Tehran, Iran) as breakfast for 1 week. After that time, saliva samples were collected in the manner previously described and used to measure salivary $\mathrm{pH}$ and the $S$. mutans count. The $2^{\text {nd }}-5^{\text {th }}$ weeks of the study were considered as a wash-out period with no pertinent data collection. Following the wash-out period, baseline saliva samples were collected and the subjects consumed regular cake as breakfast for 1 week. The saliva samples were collected for the $4^{\text {th }}$ time after the $6^{\text {th }}$ week and were used to measure $\mathrm{pH}$ and the $S$. mutans count. This protocol was also followed for the $2^{\text {nd }}$ group, but the order of probiotic and ordinary cake consumed was reversed (regular cake consumed during the $1^{\text {st }}$ week and probiotic cake consumed during the $6^{\text {th }}$ week). The subjects in both 
groups were blinded to the content of the cake consumed. Figure 1 provides a flowchart of the study protocol. The collected samples were stored at $-70^{\circ} \mathrm{C}$, and $100 \mu \mathrm{L}$ of the specimen were used to make $10^{-1}, 10^{-2}, 10^{-3}, 10^{-4}$, and $10^{-5}$ dilutions in phosphate buffered saline (PBS) and in the calibrator diluent buffer, respectively. To culture the saliva samples, the specimen was streaked on 96-well plates containing the Mitis Salivarius Agar medium (Merck, Darmstadt, Germany). The agar plates were incubated at $37^{\circ} \mathrm{C}$ for $48 \mathrm{~h}$. The bacterial colonies were counted with a colony counter using different dilutions; their mean value was reported as the final $S$. mutans count. The GC pH strips (900 200; GC America, Inc., Alsip, USA) were used for the measurement of salivary $\mathrm{pH}$. A single sheet of the GC pH strips was dipped into saliva for $40 \mathrm{~s}$ to allow complete wetting of the strip. The color change in the $\mathrm{GC} \mathrm{pH}$ strip was compared with the standard chart to determine salivary $\mathrm{pH}$.

\section{Statistical analysis}

Statistical analysis was carried out using the IBM SPSS Statistics software, v. 21.0 (IBM Corp., Armonk, USA) for Windows. The data was analyzed using the $t$-test and the paired samples method. Differences were considered significant at $p<0.05$.

\section{Results}

A total of 40 subjects were enrolled in the study. Twenty-one (52.5\%) subjects were male and 19 (47.5\%) were female. The age range of the participants was $15-73$ years with an average of $41.67 \pm 16.80$ years. Eleven subjects were smokers (at least 1 cigarette per day) and 17 participants reported having consumed alcohol regularly (at least once a day). Ten subjects were both smokers and regular alcohol drinkers and 18 of the 40 neither smoked nor drank alcohol regularly. The mean value of the S. mutans count was $6.42 \times 10^{6} \mathrm{CFU} / \mathrm{mL}$ at baseline, $6.95 \times 10^{6} \mathrm{CFU} / \mathrm{mL}$ after the weekly consumption of probiotic cake and $1.23 \times 10^{7} \mathrm{CFU} / \mathrm{mL}$ after eating regular cake for 1 week (Table 1). The mean value for salivary $\mathrm{pH}$ at baseline, after the consumption of probiotic and regular cake, was 7.125, 6.902 and 7.000, respectively (Table 1).

Table 1. Mean and standard deviation (SD) of salivary $\mathrm{pH}$ and the Streptococcus mutans (S. mutans) count at baseline and after 1-week consumption of probiotic and regular cake

\begin{tabular}{|l|c|c|}
$\begin{array}{l}\text { Status of cake } \\
\text { consumption }\end{array}$ & $\begin{array}{c}\mathrm{pH} \\
(\text { mean } \pm \text { SD) }\end{array}$ & $\begin{array}{c}\text { S. mutans count }\left(\times 10^{6}\right) \\
{[\mathrm{CFU} / \mathrm{mL}]} \\
(\text { mean } \pm S D)\end{array}$ \\
\hline Baseline & $7.125 \pm 0.493$ & $6.42 \pm 13.53$ \\
Probiotic cake & $6.902 \pm 0.231$ & $6.95 \pm 10.42$ \\
Regular cake & $7.000 \pm 0.472$ & $1.23 \pm 20.16$ \\
\hline
\end{tabular}

Table 2 summarizes the results of the statistical analysis for the salivary $S$. mutans count and $\mathrm{pH}$. Following the consumption of regular cake, the $S$. mutans count increased in comparison with the baseline $S$. mutans count and the difference was statistically significant $(p=0.027)$. Although the $S$. mutans count increased slightly after the consumption of probiotic cake in comparison with the baseline value, the difference was not statistically significant $(p=0.795)$. The mean $S$. mutans count after

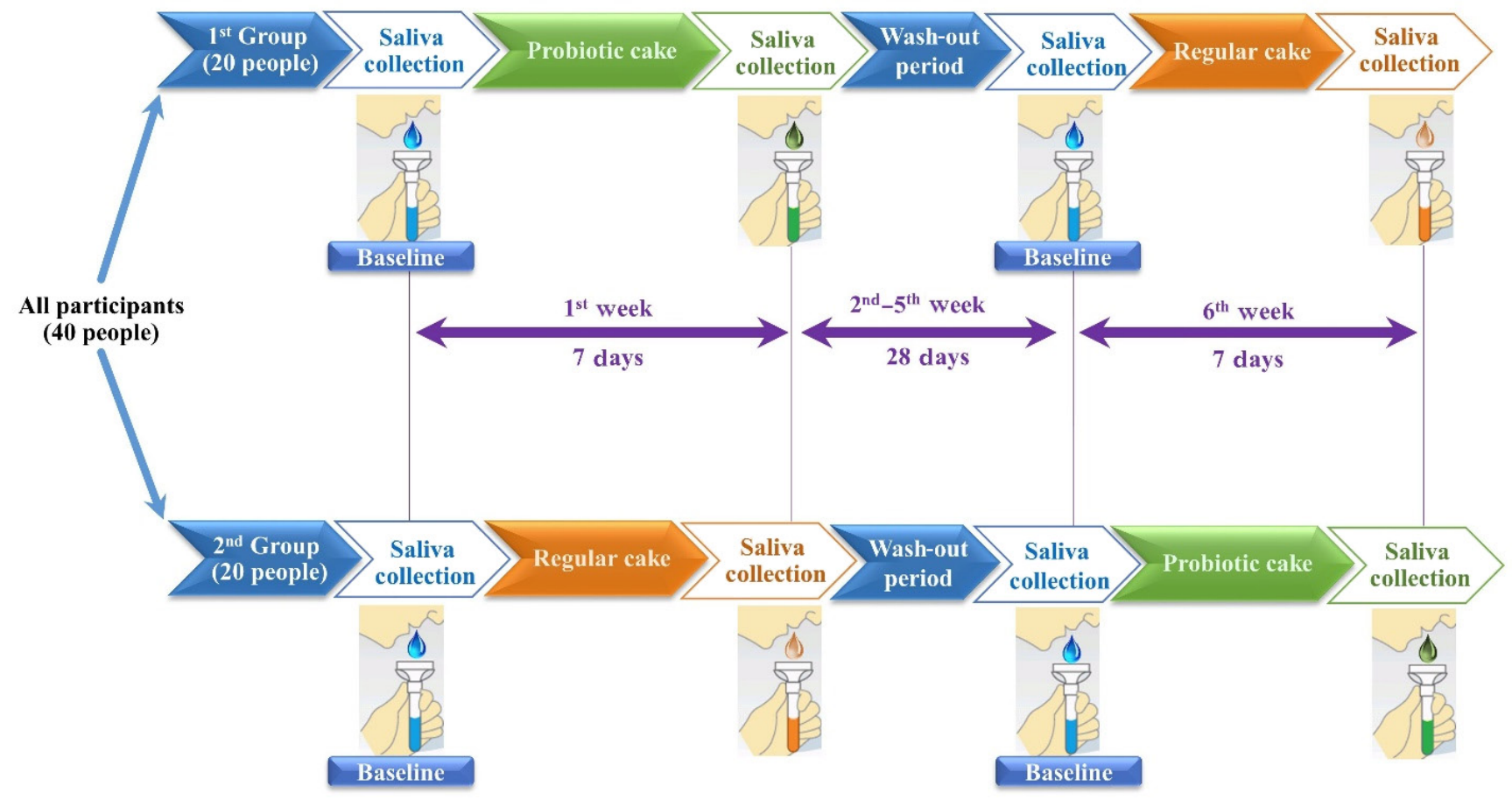

Fig. 1. Flowchart of saliva collection in the $1^{\text {st }}$ and the $2^{\text {nd }}$ group 
Table 2. Statistical analysis of the Streptococcus mutans (S. mutans) count and salivary pH at baseline and after probiotic and regular cake consumption

\begin{tabular}{|c|c|c|c|c|c|}
\hline \multirow{2}{*}{\multicolumn{2}{|c|}{ Comparison between groups }} & \multicolumn{2}{|c|}{$\begin{array}{c}\text { Paired samples correlation } \\
\text { ( } p \text {-value }) \\
\text { S. mutans count }\end{array}$} & \multirow{2}{*}{$\begin{array}{l}\text { Paired samples test } \\
\text { Sig(2-tailed) } \\
\text { ( } p \text {-value) } \\
\text { S. mutans count }\end{array}$} & \multirow{2}{*}{$\begin{array}{c}\text { Paired samples test } \\
\text { Sig(2-tailed) } \\
\text { ( } p \text {-value) } \\
\text { pH }\end{array}$} \\
\hline & & correlation & Sig & & \\
\hline Pair 1 & $\begin{array}{l}\text { average } S \text {. mutans count at baseline } \\
\text { average } S \text {. mutans count probiotic cake }\end{array}$ & 0.439 & 0.005 & 0.795 & 0.068 \\
\hline Pair 2 & $\begin{array}{l}\text { average S. mutans count at baseline } \\
\text { average S. mutans count regular cake }\end{array}$ & 0.139 & 0.392 & 0.027 & 0.723 \\
\hline Pair 3 & $\begin{array}{l}\text { average } S \text {. mutans count probiotic cake } \\
\text { average S. mutans count regular cake }\end{array}$ & 0.204 & 0.208 & 0.030 & 0.183 \\
\hline
\end{tabular}

eating regular cake was significantly higher than the mean $S$. mutans count following the consumption of probiotic cake $(p=0.030)$.

We did not detect a statistically significant difference in salivary $\mathrm{pH}$ after eating probiotic or regular cake in comparison with the baseline level, although both food types caused a minor drop in salivary $\mathrm{pH}$ (Table 2).

\section{Discussion}

Utilizing probiotics as a supplement in foods that are potentially cariogenic is an interesting approach for improving oral health, as seen in a number of recent studies aimed at controlling caries, periodontal disease and oral candidiasis..$^{20}$ In this study, we chose cake as a carrier of $B$. coagulans to reduce the $S$. mutans count. This choice is consistent with the prevalent consumption of sucrosecontaining snacks in modern societies, especially among children.

Our results showed that short-term consumption of probiotic cake did not significantly increase the $S$. $m u$ tans count in saliva, while week-long consumption of regular cake caused a significant increase in the $S$. mutans count. The results of previous studies show a similar trend. In contrast, Keller et al. demonstrated that consuming probiotic-containing tablets did not significantly reduce the $S$. mutans count. ${ }^{21}$ Siddiqui et al. showed that the consumption of probiotic-containing dairy products decreased the $S$. mutans count. ${ }^{22}$ In several studies, a reduction in the $S$. mutans count with the consumption of probiotic-containing dairy products or lozenges was significant. ${ }^{23,24}$ Our study differs from previous research with respect to the design, choice of probiotic species and the carrier food, period when the probiotic food was consumed, and culture medium. In addition, the dairy products utilized in earlier studies did not contain glucose or sucrose, both of which are shown to increase the $S$. mutans count. ${ }^{22,25}$

Two review studies, by Laleman et al. and SeminarioAmez et al., provide support for the efficacy of probiotics in reducing the $S$. mutans count. ${ }^{11,20}$ The role of $S . m u$ tans in cariogenesis is well-established and despite the inadequacy of evidence for caries prevention properties of probiotics, a reduction in the $S$. mutans count is a step forward. ${ }^{7}$ We did not find a significant difference in the baseline $S$. mutans count between smokers and nonsmokers. This observation is consistent with the findings of Sheth et al. and Voelker et al. ${ }^{26,27}$ Our results show that the consumption of regular cake in smokers greatly increased the count of S. mutans bacteria and the rate of increase in smokers was much higher than in non-smokers. Compared to regular cake, the consumption of probiotic cake caused a much smaller change in the $S$. mutans count in both smokers and non-smokers. The difference in the $S$. mutans count after the consumption of probiotic cake compared to regular cake was greater in smokers than in non-smokers. The consumption of probiotic cake in smokers led to a much smaller increase in the $S$. mutans count compared to that observed with regular cake, while the consumption of probiotic cake in non-smokers caused a reduction in the $S$. mutans count. A plausible explanation for the lower efficacy of probiotic cake in reducing the $S$. mutans count in smokers is tobacco smoke-induced disturbance of oral microflora and its interactions with the probiotic species. ${ }^{28,29}$

Our results show a higher S. mutans count among the subjects who regularly consumed alcohol compared to those who did not regularly drink alcohol in all groups. This finding contradicts the results reported by Sheth et al. ${ }^{26}$ It may be attributed to the difference in the study design, amount and type of alcohol as well as duration of drinking. In the subjects who regularly consumed alcohol, the consumption of regular cake increased the S. mutans count compared to the baseline. In comparison with regular cake, the $S$. mutans count increased slightly with the consumption of probiotic cake, irrespective of alcohol use, and the increase in the $S$. mutans count was more pronounced in the subjects who were not habitual users of alcohol. This difference may be attributed to the bacteriostatic effects of some types of alcohols on oral microflora. The consumption of regular cake by the users of both substances (alcohol and tobacco) increased the S. mutans count. A similar but less pronounced trend was also observed with the probiotic cake consumption in the subjects who both smoked and used alcohol regularly. Cigarette smoking reduces salivary $\mathrm{pH}$, which predisposes the hard and soft tissues of the oral cavity to a variety 
of diseases over time. ${ }^{30}$ The highest level of $S$. mutans at baseline was observed in the non-smoker alcoholic subjects and the lowest level of $S$. mutans at baseline referred to the non-alcoholic smoker subjects. The highest level of $S$. mutans after the consumption of regular cake was observed in smokers that simultaneously consumed alcohol. The highest value of the $S$. mutans count after eating probiotic cake was observed in smokers who simultaneously consumed alcohol as well. In all groups, except for the non-smoker alcoholics, the consumption of regular cake led to a significant increase in the $S$. mutans count.

\section{Conclusions}

Although the development of dental caries depends on a complex interaction between the host's oral flora and diet, the role of $S$. mutans in cariogenesis is well-accepted. The addition of probiotic bacteria (B. coagulans) to sweet snack cake caused a minimal increase in the salivary count of $S$. mutans, but did not impact salivary $\mathrm{pH}$. As probiotic cake has a low impact on the $S$. mutans count, it is preferred over regular cake as a snack food. Considering the frequent consumption of snacks such as cakes, in modern societies, the addition of probiotic flora (B. coagulans) to cakes may offer a strategy for reducing the $S$. mutans count in the oral cavity.

\section{ORCID iDs}

Maryam Koopaie (1) https://orcid.org/0000-0002-9999-1443 Mahnaz Fatahzadeh (1) https://orcid.org/0000-0002-0720-4589 Sana Jahangir (1) https://orcid.org/0000-0002-3852-6687 Ronak Bakhtiari (1) https://orcid.org/0000-0002-3778-5732

\section{References}

1. Glanville J, King S, Guarner F, Hill C, Sanders ME. A review of the systematic review process and its applicability for use in evaluating evidence for health claims on probiotic foods in the European Union. Nutr J. 2015;14(1):16.

2. Vuong CN, Chou WK, Hargis BM, Berghman LR, Bielke LR. Role of probiotics on immune function and their relationship to antibiotic growth promoters in poultry: A brief review. Int J Probiotics Prebiotics. 2016;11(1):1-6.

3. Mansouri-Tehrani HA, Rabbani-Khorasgani M, Hosseini SM, Mokarian F, Mahdavi H, Roayaei M. Effect of supplements: Probiotics and probiotic plus honey on blood cell counts and serum IgA in patients receiving pelvic radiotherapy. J Res Med Sci. 2015;20(7):679-683.

4. Ericson D, Hamberg K, Bratthall G, Sinkiewicz-Enggren G, Ljunggren $\mathrm{L}$. Salivary $\lg \mathrm{A}$ response to probiotic bacteria and mutans streptococci after the use of chewing gum containing Lactobacillus reuteri. Pathog Dis. 2013;68(3):82-87.

5. dos Reis SA, da Conceição LL, Siqueira NP, Rosa DD, da Silva LL, Peluzio MCG. Review of the mechanisms of probiotic actions in the prevention of colorectal cancer. Nutr Res. 2017;37:1-19.

6. Lamont RJ, Jenkinson HF. Introduction to oral microbiology. In Oral Microbiology at a Glance. Singapore: Wiley-Blackwell; 2010:3.

7. Gruner D, Paris S, Schwendicke F. Probiotics for managing caries and periodontitis: Systematic review and meta-analysis. J Dent. 2016;48:16-25.

8. Nirmala M, Smitha S, Kamath GJ. A study to assess the efficacy of local application of oral probiotic in treating recurrent aphthous ulcer and oral candidiasis. Indian J Otolaryngol Head Neck Surg. 2017;69(1):1-5
9. Montero $\mathrm{E}$, Iniesta $\mathrm{M}$, Rodrigo $\mathrm{M}$, et al. Clinical and microbiological effects of the adjunctive use of probiotics in the treatment of gingivitis: A randomized controlled clinical trial. J Clin Periodontol. 2017;44(7):708-716.

10. Ghazal TS, Levy SM, Childers NK, et al. Mutans streptococci and dental caries: A new statistical modeling approach. Caries Res. 2018;52(3):246-252.

11. Laleman I, Detailleur V, Slot DE, Slomka V, Quirynen M, Teughels W. Probiotics reduce mutans streptococci counts in humans: A systematic review and meta-analysis. Clin Oral Investig. 2014;18(6):1539-1552.

12. Keller MK, Hasslöf $P$, Stecksén-Blicks C, Twetman S. Co-aggregation and growth inhibition of probiotic lactobacilli and clinical isolates of mutans streptococci: An in vitro study. Acta Odontol Scand. 2011;69(5):263-268.

13. Ashwin D, Ke V, Taranath M, Ramagoni NK, Nara A, Sarpangala M. Effect of probiotic containing ice-cream on salivary mutans streptococci (SMS) levels in children of 6-12 years of age: A randomized controlled double blind study with six-months follow up. J Clin Diagn Res. 2015;9(2):ZC06-09.

14. Srivastava S, Saha S, Kumari M, Mohd S. Effect of probiotic curd on salivary $\mathrm{pH}$ and Streptococcus mutans: A double blind parallel randomized controlled trial. J Clin Diagn Res. 2016;10(2):ZC13-16.

15. Santiago-López L, Hernández-Mendoza A, Garcia HS, Mata-Haro V, Vallejo-Cordoba B, González-Córdova AF. The effects of consuming probiotic-fermented milk on the immune system: A review of scientific evidence. Int J Dairy Technol. 2015;68(2):153-165.

16. Bahmani F, Tajadadi-Ebrahimi M, Kolahdooz F, et al. The consumption of synbiotic bread containing Lactobacillus sporogenes and inulin affects nitric oxide and malondialdehyde in patients with type 2 diabetes mellitus: Randomized, double-blind, placebo-controlled trial. J Am Coll Nutr. 2016;35(6):506-513.

17. Majeed M, Majeed S, Nagabhushanam K, Natarajan S, Sivakumar A, Ali F. Evaluation of the stability of Bacillus coagulans MTCC 5856 during processing and storage of functional foods. Int J Food Sci Technol. 2016;51(4):894-901.

18. Salvetti E, Orrù L, Capozzi V, et al. Integrate genome-based assessment of safety for probiotic strains: Bacillus coagulans GBI-30, 6086 as a case study. Appl Microbiol Biotechnol. 2016;100(10):4595-4605.

19. Abhari K, Shekarforoush SS, Hosseinzadeh S, Nazifi S, Sajedianfard J, Eskandari $\mathrm{MH}$. The effects of orally administered Bacillus coagulans and inulin on prevention and progression of rheumatoid arthritis in rats. Food Nutr Res. 2016;60(1):30876.

20. Seminario-Amez M, López-López J, Estrugo-Devesa A, Ayuso-Montero $\mathrm{R}$, Jané-Salas E. Probiotics and oral health: A systematic review. Med Oral Patol Oral Cir Bucal. 2017;22(3):e282-288.

21. Keller M, Hasslöf $P$, Dahlén G, Stecksén-Blicks $C$, Twetman S. Probiotic supplements (Lactobacillus reuteri DSM 17938 and ATCC PTA 5289) do not affect regrowth of mutans streptococci after fullmouth disinfection with chlorhexidine: A randomized controlled multicenter trial. Caries Res. 2012;46(2):140-146.

22. Siddiqui M, Singh C, Masih U, Chaudhry K, Hegde DY, Gojanur S. Evaluation of Streptococcus mutans levels in saliva before and after consumption of probiotic milk: A clinical study. J Int Oral Health. 2016;8(2):195-198.

23. Bhalla M, Ingle NA, Kaur N, Yadav P. Mutans streptococci estimation in saliva before and after consumption of probiotic curd among school children. J Int Soc Prev Community Dent. 2015;5(1):31-34.

24. Caglar E, Kuscu OO, Cildir SK, Kuvvetli SS, Sandalli N. A probiotic lozenge administered medical device and its effect on salivary mutans streptococci and lactobacilli. Int J Paediatr Dent. 2008;18(1):35-39.

25. Salli K, Forssten S, Lahtinen S, Ouwehand A. Influence of sucrose and xylitol on an early Streptococcus mutans biofilm in a dental simulator. Arch Oral Biol. 2016;70:39-46.

26. Sheth CC, Makda K, Dilmahomed Z, et al. Alcohol and tobacco consumption affect the oral carriage of Candida albicans and mutans streptococci. Lett Appl Microbiol. 2016;63(4):254-259.

27. Voelker MA, Simmer-Beck M, Cole M, Keeven E, Tira D. Preliminary findings on the correlation of saliva $\mathrm{pH}$, buffering capacity, flow, consistency and Streptococcus mutans in relation to cigarette smoking. J Am Dent Hyg Assoc. 2013;87(1):30-37.

28. Tsigarida A, DabdoubS, Nagaraja HN, Kumar P. The influence of smoking on the peri-implant microbiome. J Dent Res. 2015;94(9):1202-1217. 
29. Nagarajan R, Miller CS, Dawson D III, Al-Sabbagh M, Ebersole JL. Cross-talk between clinical and host-response parameters of periodontitis in smokers. J Periodontal Res. 2017;52(3):342-352.

30. Grover N, Sharma J, Sengupta S, Singh S, Singh N, Kaur H. Longterm effect of tobacco on unstimulated salivary $\mathrm{pH}$. J Oral Maxillofac Pathol. 2016;20(1):16-19. 